\title{
Engagement Relation with Self-Awareness and Cognitive Assimilation Efficiency of Students
}

\author{
Dr. Muntaha Mutashar Abdulsahib ${ }^{1}$, Dr. Jamal Hameed Kasim² \\ ${ }^{1,2}$ Assistant Professor, Baghdad University, Education College for Pure Sciences/Ibn Al-Haitham/Psychological and Educational Sciences \\ Section
}

\begin{abstract}
The current research aims to identify the relation between the engagement and self-awareness on one hand and the cognitive assimilation efficiency on the other hand. The research was confined to Baghdad university students, primary day study for 2014-2015 with the total community of (41249) he/she students. The research sample amounted 400 he/she students of whom (112) are males and (118) females divided into (200) students in the scientific specialization and (200) students in the humanitarian specialization. Three tools were used which are the Engagement scale (CCSSE) prepared in 2008, Self-awareness scale of (AlQaragholi, in 2011) and Cognitive assimilation efficiency of (Al-Mujli) in 2016. The two researchers extracted the reliability and validity of these three scales by using the statistic means represented by $T$ test of one sample and $T$ test of discrepancy between the two correlation factors and then reaching the outcomes that indicate the existence of positive and correlative and statistic significance between the engagement, self-awareness and cognitive assimilation efficiency and the existence of differences in the relation significance between the engagement, self-awareness and cognitive assimilation efficiency in accordance with between the two variables of gender and specialization in favor of males and scientific specialization. In light of the above-mentioned, a number of recommendations and proposals were set.
\end{abstract}

Keywords: Engagement, Self-awareness, Cognitive assimilation efficiency, University students

\section{Introduction}

The importance of any search is to identify the problems suffered by individuals and try to surround and treat it. University students are considered an important social category in the country as they are the future leaders on whose shoulders lies the responsibility of steering the progress wheel in the future. Therefore, we have to determine their social and psychological status as well as their problems.

The engagement is important variables in university students' life which helps reducing student dropout and graduation delay and wastage of time and money resulted from that delay. It also helps student in optimizing the scientific point of view (Misty, 2013, p.19).

Engagement can be defined as the amount of time and energy invested in the student's guided educational activities through participation, such as attendance and performance of duties and others, following teachers' class instructions and student readiness to contribute in university activities in the following fields:

- The active cooperative learning,

- student effort,

- academic challenges,

- student interaction with board of teachers

- Providing support to learners.

(Maria, 2012, p.15) (CCSSE, 2006, A)

An extensive survey on university engagement was conducted and titled (Community College Survey of Students engagement) or (CCSSE). A tool was used to measure engagement in the university and this tool was used based on the theorists (Paces 1984, Astin 1984, Chickering and Gamson 1987, Kuh 2001 and Mcclenny 2007, p.143).
There are types of engagement such as the cognitive that includes the student's engagement in the educational content and skills; the sympathetic engagement which indicates the negative and positive feelings towards teachers and colleagues; and the behavioral engagement that includes students' behavior and participation the extra -curricular activities.

The non-engagement of university student creates many problems and it must be studied especially in the communities suffer from different problems like the current Iraqi society. Self-awareness helps individual controlling various confrontations and self-motivation, sympathy and personal behavior which are considered the most emotional and social skills that characterize the persons who are most successful in the social life particularly in study (Goleman, 1995, p.4). The self-awareness helps individual to realize and overcome problems he faces and be able to interpret the relations between his exerted effort and the consequences of solving the problem (Al-fatlawi 2008, p.31).

The self-awareness can be defined as the individual's ability to direct the attention either towards his ego or outside it (environment) and this attention direction causes a case of temporary assessment (Buss, 1980, p.54).

Prentice-Dunn and Rogers (1982) thinks that the selfawareness is of two types, the first is the special selfawareness that indicates the focus of attention in the personal feelings and thoughts we pay to our thoughts, feelings and emotions. It may be decreased when the individual is within the group and forget himself and deserves the emotional attitudes (Prentice and Dunn and Rogers 1982, p.503-513.

The second type is the public self-awareness that demonstrates the attention and the interest in people 


\section{International Journal of Science and Research (IJSR) \\ ISSN (Online): 2319-7064}

Index Copernicus Value (2015): 78.96 | Impact Factor (2015): 6.391

impression towards the individual that may be decreased when the individual is among the others and it is difficult to identify it as the individual is unknown for others. This might lead to responsibility distribution at the time of social acts that can be characterized as chaotic and aggressive because the members of the group conducting these acts are presenting a model for others to follow (Mklfeen and Ghroose, 2002 p.102).

Apart from the self-awareness, the engagement requires that the individual has the ability to face the problems by a way of keeping huge and suitable base of integrated, organized and correlated data that enables him to derive the signs of meanings and thoughts at different levels of cognitive complexity and highly efficient plans that helps him understand and deal with different problems( Azeez 2016, p.20) and this is called the efficiency of the cognitive assimilation which can be defined as the usage and placement of meanings, thoughts and mental perceptions to be a part of the permanent component of the individual's cognitive structure (Al-Zayat, 1998, p.288).

Knowledge owners think that the cognitive assimilation is a process of transforming the various experiences and arousals to professional meanings, thoughts and perceptions that can be coded, comprehended and placed in an organized way to become part of the individual's permanent cognitive structure in terms of the long-term memory and his cognitive tools of constant interaction with the world around him where the information is reorganized and assimilated in a way with which the information becomes ready to be retrieved when needed ( Al-Zayat, 2006, p.227).

The cognitive approach adopts the assumption that the learner interacts in the learning with what experience and organized and non-organized situation. The learner develops and grows in his interaction with those experiences through the mental and cognitive processes such as organization , usage, incorporation and storing what experiences he interacted with that will evolve special experiences with which he identify the way of his thinking and learning ( Abdulrahman , 2003, p.167).

Despite the existence of studies that addressed the current research, it did not study the relation between the variables of engagement and the self-awareness and the cognitive assimilation efficiency of university students. This research is a trial to bridge the scientific gap in these variables and to identify the strength and direction of the relation between engagement and the self-awareness and the cognitive assimilation efficiency apart from the differences in the correlative relation among these variables according to the two variables of gender( male, female) and specialization ( scientific, humanitarian).

\section{Research Procedures}

Firstly/ research community and sample: the research community is restricted in Baghdad university students/ the primary day study of the first four stages for year 20142015 that amounted 41249 students ( 16901 males and 24384 females) and they are distributed in accordance with the specialization ( 26593 in the humanitarian and 14656 in the scientific).

A random sample of 400 students (she and he) was taken and it was distributed into 200 students in the scientific specializations and 200 students in the humanitarian ones as shown in the following table:

\begin{tabular}{|c|c|c|c|}
\hline Specialization & Males & Females & Total \\
\hline Scientific & 94 & 106 & 200 \\
\hline Humanitarian & 118 & 82 & 200 \\
\hline Total & 212 & 188 & 400 \\
\hline
\end{tabular}

Secondly/ research tools:

The following tools were adopted to achieve the research goal:

1)Engagement scale,( CCSSE, 2008) ( Community College Survey of Students Engagement, which is composed of 37 items divided into five fields as follows:

a) Active and collaborative learning;

b) Student Effort;

c) Faculty Student-Interaction;

d) Support for Learners;

e) Academic Challenge.

Each one of the five items of the scale has alternatives which are: always applied to me; often applied to me; sometimes applied to me; rarely applied to me; never applied to me. The scales 5, 4, 3, 2, 1 are applied to the positive items and the opposite is applied to the negative items which are only no.11 and 37.

2)Self-Awareness Scale: self-awareness scale prepared by Al-Qaragholi in 2011 was used it is composed of 26 items distributed into two fields which are the private selfawareness that includes 14 items, and the second isthe public environmental self-awareness that includes 12 items. Each item of the scale has five alternatives which are: completely applied to me; very much applied to me; moderately applied to me; a little applied to me; never applied to me. The scales 5, 4, 3, 2,1 are applied to the positive items that carry the numbers ( $2,3,5,6,7,8,10,14,16,17,21,22,23,24,26)$ and the remaining items takes the opposite scales.

3)Cognitive assimilation efficiency scale: The researcher applied the cognitive assimilation efficiency scale prepared by Wurood Razaq Mjli in 2016 which is comprised of 28 items distributed into 4 fields which are: inputting, comprehension, coding, placement and sustainability. It is adjusted according to a sliding scale of five alternatives which are: completely applied to me; often applied to me; sometimes applied to me; not applied to me; and never applied to me and the scales $5,4,3,2,1$ applied to the positive items and the scales $1,2,3,4,5$ are applied for the remaining negative items. 


\section{International Journal of Science and Research (IJSR) \\ ISSN (Online): 2319-7064}

Index Copernicus Value (2015): 78.96 | Impact Factor (2015): 6.391

\begin{tabular}{|c|c|c|c|c|c|}
\hline Number of sample individual & Arithmetic mean & $\begin{array}{c}\text { Standard } \\
\text { deviation }\end{array}$ & $\begin{array}{c}\text { Presumptuous } \\
\text { mean }\end{array}$ & \multicolumn{2}{|c|}{ T Value } \\
\cline { 3 - 6 } & & 122,6 & 111 & 1,96 & 1,96 \\
\hline
\end{tabular}

In order to verify the reliability of the three scales, detection for their liability and confirmation was conducted as the following:

Firstly: extract the apparent validity by offering the three scales to a group of experts specialized in psychometrics and psychology, and all have approved the items of the three scales depending on the percentage as a standard to accept the item in each scale. The approval of $80 \%$ or more of the experts was considered a standard to accept the item.

Secondly: scale reliability: the split into halves method was used to identify the reliability of the three scales through applying the scale to a sample of students of Baghdad university/ college of education/ Ibn Rushd/ Geography section and they were 100 he/she students to find the relation between the even and odd items in each scale by using Person's correlation factor in the scale of self-awareness, the cognitive assimilation scale and Horst formula for the engagement scale because the number of its items is 37 odd items and the results of the reliability is as follow:

Thirdly: Application procedures

After verification of reliability and validity of the two scales, the third scale was applied to the survey sample of 400 he/she students.

Fourthly: survey results: the survey reached the outcomes according to the following targets:
1)Identify the level of engagement of university students and to achieve this target, the arithmetic mean of students' scores was extracted on the engagement scale and also the standard deviation was extracted. After comparing the two arithmetic and presumptuous means by using $\mathrm{T}$ test to one sample, the results are as shown in the following table ( 2):

Table 2: T test outcomes to extract difference significance between two arithmetic and presumptuous means on the engagement scale

\begin{tabular}{|c|c|c|}
\hline No & Scale Name & Degree of Reliability \\
\hline 1 & Engagement & $86 \%$ \\
\hline 2 & Self-awareness & $88 \%$ \\
\hline 3 & Cognitive assimilation efficiency & $76 \%$ \\
\hline
\end{tabular}

Table 2 shows that the accounted $\mathrm{T}$ value of 1,92 is less than the table $\mathrm{T}$ value with significance level of 0,05 and a freedom degree of 399 which indicates the existence of discrepancies with statistical significance in favor of the arithmetic mean of the sample which means that the university students have engagement and this is a positive outcome and an indication that they are still keen to perform the requirement of the university work such as the study and social relations.

\section{1) Identify self-awareness level of university students}

To achieve this target, the arithmetic mean of students' scores was extracted on the self-awareness and presumptuous means and also the standard deviation was extracted. T test was applied to one sample to identify discrepancy significance between the arithmetic and presumptuous means. Table 3 shows the following details:

Table 3:T test outcomes to extract difference significance between two arithmetic and presumptuous means on the

\begin{tabular}{|c|c|c|c|c|c|c|}
\hline Number of sample & Arithmetic & Standard & Presumptuous & \multicolumn{2}{|c|}{ T Value } & Significance \\
\cline { 5 - 6 } individuals & mean & deviation & mean & accounted & In table & level \\
\hline 400 & 79,13 & 7,43 & 75 & 3,740 & 1,96 & 0.05 \\
\hline
\end{tabular}

Table 3 shows that the accounted $\mathrm{T}$ value of 3, 740 is bigger than the table $\mathrm{T}$ value with significance level of 0,05 and a freedom degree of 399 which indicates that university students have self-awareness and this is also a positive outcome and in favor of university's students.

\section{2)Identify the cognitive assimilation efficiency of students.}

To achieve this target, the arithmetic mean and the standard deviation of students' scores was extracted on the cognitive assimilation efficiency scale. The presumptuous means of the scale that amounted (84) was also extracted by applying $\mathrm{T}$ test to one sample to identify discrepancy significance between the arithmetic and presumptuous means. Table 4 shows the following details:
Table 4: Difference significance between two arithmetic and presumptuous means on the cognitive assimilation efficiency

\begin{tabular}{|r|c|c|c|c|c|}
\hline Gender & $\begin{array}{c}\text { Number of } \\
\text { sample } \\
\text { individuals }\end{array}$ & $\begin{array}{c}\text { Correlation } \\
\text { factor } \\
\text { value }\end{array}$ & \multicolumn{2}{|c|}{ T Value } & accounted \\
Males & 212 & 0,88 & 11.702 & 1,96 & 0,05 \\
table & level \\
\hline Females & 188 & 0,79 & & & \\
\hline
\end{tabular}

Table 4 shows that the accounted $\mathrm{T}$ value of 0,019 is less than the table $\mathrm{T}$ value of 1,96 with significance level of 0,05 and a freedom degree of 399 which indicates the nonexistence of discrepancies with statistical significance in the cognitive assimilation which means that university students have cognitive assimilation.

1. Identify the relation between the engagement and selfawareness: 


\section{International Journal of Science and Research (IJSR) \\ ISSN (Online): 2319-7064 \\ Index Copernicus Value (2015): 78.96 | Impact Factor (2015): 6.391}

To achieve this target, the correlative relationship between the students' scores on the scale of engagement and selfawareness by using Person's correlation factor which value was $(0,83)$ and it is new correlation factor. Studies and references indicate that correlation factor value, that amounted $(0,70)$ or more, is considered good value.

2. Identify the differences in the relation between the engagement and the self-awareness according to the two variables of (gender/ males, females) and specialization (scientific, humanitarian).

To identify the differences in the relation between the engagement and the self-awareness according to the two variables of (gender/ males, females) and specialization (scientific, humanitarian), the correlation factors of each gender of all sample individual was separately extracted. In addition, the correlation factorsof all male and female student for each of the scientific and humanitarian specialization. T test was applied to identify differences significance between the two correlation factors to extract differences significance between males and females.Table 5 shows the following details:

Table 5: Discrepancy significance between the two correlation factors based on gender variable

\begin{tabular}{|c|c|c|c|c|c|}
\hline Specialization & $\begin{array}{c}\text { Number } \\
\text { of sample } \\
\text { individuals }\end{array}$ & $\begin{array}{c}\text { Correlation } \\
\text { factor } \\
\text { value }\end{array}$ & \multicolumn{2}{|c|}{ T Value } & Significance \\
level & $\begin{array}{c}\text { accounted } \\
\text { table }\end{array}$ & \\
\hline Scientific & 200 & 0,85 & 11,790 & 1,96 & 0,05 \\
\hline Humanitarian & 200 & 0,83 & & & \\
\hline
\end{tabular}

Table 5 shows that the accounted $\mathrm{T}$ value of the differences significance between the two correlation factors of $(11,702)$ is bigger than the table $T$ value of $(1,96)$ with significance level of 0,05 and a freedom degree of 398 which indicates that there are statistic discrepancies significances between the two correlation factors in favor of males, which means that the relation between the engagement and self-awareness of males is stronger than females one. University students have self-awareness and this is also a positive outcome and in favor of university's students. Regarding specialization variable, the outcomes are shown as follow:

Table 6: Discrepancy significance between the two correlation factors based on specialization variable

\begin{tabular}{|c|c|c|c|c|c|c|}
\hline \multirow{2}{*}{$\begin{array}{c}\text { Number of } \\
\text { sample } \\
\text { individuals }\end{array}$} & \multirow{2}{*}{$\begin{array}{c}\text { Arithmetic } \\
\text { mean }\end{array}$} & \multirow{2}{*}{$\begin{array}{c}\text { Standard } \\
\text { deviation }\end{array}$} & \multirow{2}{*}{$\begin{array}{c}\text { Presumptuous } \\
\text { mean }\end{array}$} & \multicolumn{2}{|c|}{ T Value } & Significance \\
\cline { 5 - 7 } & & & accounted & In table & level \\
\hline 400 & 80,05 & 3,160 & 84 & 0.019 & 1,96 & 0,05 \\
\hline
\end{tabular}

Table 6 shows that the accounted $\mathrm{T}$ value of $(11,790)$ is bigger than the table $\mathrm{T}$ value of $(1,96)$ with significance level of 0,05 and a freedom degree of 398 which indicates that there are statistic discrepancies significances between the two correlation factors in favor of scientific specialization, which means that the relation between the engagement and self-awareness of scientific specialization is stronger than humanitarian specialization.

3. Identify the correlative relation between the engagement and cognitive assimilation efficiency variables: It was verified by finding the correlative relationship between all students' scores on the scale of engagement and cognitive assimilation efficiency by using Person's correlation factor which value was $(0,74)$ and it is accepted correlation factor value that indicates the existence of a positive relation where the correlation factor value ranges between ( -1 and $+1)$.

4. Identify the discrepancies in the relation between the engagement and cognitive assimilation efficiency: In order to identify the discrepancies according to these two variables, the correlation factors of each males and females of all sample individuals were separately counted and then the correlation factors between the two variables both of males and females for the scientific specialization alone and the humanitarian specialization. In order to identify the discrepancies in accordance with gender variable, $\mathrm{T}$ test was applied to identify discrepancy significance between the two correlation factors. Table 7 shows the following details:
Table 7: Discrepancies in the relation between the two correlation factors based on gender variable

\begin{tabular}{|c|c|c|c|c|c|}
\hline \multirow[t]{2}{*}{ Gender } & \multirow{2}{*}{$\begin{array}{l}\text { Number of } \\
\text { sample } \\
\text { individuals }\end{array}$} & \multirow{2}{*}{$\begin{array}{l}\text { Correlation } \\
\text { factor value }\end{array}$} & \multicolumn{2}{|c|}{ T Value } & \multirow{2}{*}{$\begin{array}{c}\text { Significance } \\
\text { level }\end{array}$} \\
\hline & & & eccounted & $\begin{array}{c}\text { In } \\
\text { table }\end{array}$ & \\
\hline males & 212 & 0,78 & \multirow[t]{2}{*}{10.441} & \multirow[t]{2}{*}{1,96} & \multirow[t]{2}{*}{0,05} \\
\hline females & 188 & 0,71 & & & \\
\hline
\end{tabular}

Table 7 shows that the accounted $T$ value of (10.441) is bigger than the table $\mathrm{T}$ value of $(1,96)$ with significance level of 0,05 and a freedom degree of 398 which indicates that there are statistic discrepancies significances between the two correlation factors in favor of males, which means that the relation between the engagement and cognitive assimilation efficiency of males is stronger than the relation between these two variables of females.

In order to identify the discrepancies in accordance with specialisation variable, $\mathrm{T}$ test was applied to identify discrepancies between the two correlation factors. Table 8 shows the following details:

Table 8: Discrepancies in the relation between the engagement and cognitive assimilation efficiency based on specialization variable

\begin{tabular}{|c|c|c|c|c|c|}
\hline \multirow[t]{2}{*}{ Specialization } & \multirow{2}{*}{$\begin{array}{c}\text { Number } \\
\text { of sample } \\
\text { individuals }\end{array}$} & \multirow{2}{*}{$\begin{array}{c}\text { Correlation } \\
\text { factor }\end{array}$} & \multicolumn{2}{|c|}{ T Value } & \multirow{2}{*}{$\begin{array}{c}\text { Significance } \\
\text { level }\end{array}$} \\
\hline & & & accounted & $\begin{array}{c}\text { In } \\
\text { table }\end{array}$ & \\
\hline Scientific & 200 & 0,82 & \multirow[t]{2}{*}{7,017} & \multirow[t]{2}{*}{1,96} & \multirow[t]{2}{*}{0,05} \\
\hline Humanitarian & 200 & 0,72 & & & \\
\hline
\end{tabular}

Table 8 shows that the accounted $T$ value of $(7,017)$ is bigger than the table $\mathrm{T}$ value of $(1,96)$ with significance 


\section{International Journal of Science and Research (IJSR) \\ ISSN (Online): 2319-7064 \\ Index Copernicus Value (2015): 78.96 | Impact Factor (2015): 6.391}

level of 0,05 and a freedom degree of 398 which indicates that there is statistic discrepancy significance in favor of scientific specialization, which means that the relation between the engagement and cognitive assimilation efficiency of scientific specialization is stronger than the relation between these two variables of humanitarian specialization.

\section{Research Outcomes Discussion}

1)University students in Iraq have, despite of the hard political circumstances the country undergoes, engagement and self-awareness apart from cognitive assimilation efficiency and this confirms that the circumstances do not impact these variables and the crises might be a motivation for the student to be more engaged, has self-awareness and be more thoughtful, attentive and assimilative of information and sciences.

2)The engagement has a relation with self-awareness and cognitive assimilation efficiency and it is a positive relation with statistical significance and shows that selfawareness and cognitive assimilation efficiency may be the active variables that make the student more engaging and has the ability to realize the surrounding social environment and situation, be more able to assimilate and understand knowledge, values his potentials and subsequently upholds his social and scientific level.

3)The value of relation between engagement and selfawareness in on hand, and engagement and the cognitive assimilation efficiency on the other hand is stronger in the males in comparison with relation between these variables in females and this confirms that male are more able to assimilate knowledge and this might be due to the nature of social environment in which males grew up in Iraqi society which gives a greater role to run life and living matters and subsequently they become more ready to receive life experiences and its relevant issues which will be reflected on their nature and personal efficiency.

4)The value of relation between engagement and selfawareness in on hand, and engagement and the cognitive assimilation efficiency on the other hand is higher in the scientific specializations in comparison with humanitarian specializations and this indicates that the specialization has a relation with self-awareness and personal efficiency of the individual.

\section{Recommendations}

Based on the research outcomes, the two researchers recommend the following:

1)Urge the universities to have a role in developing selfawareness and the cognitive assimilation efficiency of its students especially those in the humanitarian specializations.

2)Raise social awareness towards the necessity of giving the females a greater role in life through granting them a greater freedom in terms of behavior to strengthen their self-awareness and knowledge efficiency.

\section{Proposals}

The two researchers recommend the following:

1) Conduction of studies similar to this research on other samples other than university students like secondary schools' students.

2) 2-Conduction of studies to identify the relation of engagement with other variables such as personality patterns and thinking approaches.

\section{References}

[1] Abdlrahman Eessa and Yousif Qatami (2003) Educational Psychology. Theory and basic practice, Dar Al-Fikr House, Amman.

[2] Azeez Tuqa Badri (2016) Self-awareness and its relation with social persuasion of university students, unpublished Master Thesis, College of education for pure sciences, Ibn Al-Haitham , Baghdad University.

[3] Buss A.H (1980) Self-consciousness and social anxiety, university of Texas, W.H.Freeman Company.

[4] Community college survey of students engagement (2006 a), Act on fact, Using data to improve students success, retrieved December 15, 2006.

[5] Al-Fatlawi, Ali Shakir (2008), Introduction to time Psycology, Burhan printing house, Baghdad

[6] Goleman, M. (1995) Emotional intelligence, Bantam book, New York.

[7] Maria Uriadich (2012) Predicting the engagement of first generation Community college students $=\mathrm{A}$ Quantitative study using CCSSE data, California Irvine

[8] Misty, R. Steele (2013) Exploring pre-service teacher's perceptions of academic engagement at college students, Oklahoma, Chickasha;

[9] Mujali, Wurood Razaq (2016) Cognitive assimilation efficiency and its relationship with cognitive speed of university students, unpublished Master Thesis, College of education, Al-Qadisiah University.

[10] Prentice Dunn and Rogers R.W (1982) Effect of public and private self-awareness deviation and aggression, journal of personality and social psychology.

[11] Mclfeen, Robert, Gross Richard (2002) Introduction to social psychology, translated by Yasmin Hadad and Ouda Al-Hamdani, Wail publishing house, Amman.

[12] Al-Zayat Fathi Mustafa (1998) Biological and psychological bases of the mental and cognitive activity, universities publishing house, Cairo.

[13] Al-Qaragholi, Hassan Ahmed (2011) Self-awareness and its relation with social confrontation and resistance of temptation of university students, unpublished $\mathrm{PhD}$ thesis, College of education, Mustansyriah University.

[14] Al-Zayat Fathi Mustafa (2006) Cognitive bases of mental and cognitive configuration, and information provision, F (2), universities publishing house, Cairo. 